\title{
A Course-Based Qualitative Inquiry: What Relational-Centred Practice Looks Like When in a Power-Over Position of Authority
}

\author{
Adrianna Cambridge \\ BCYC, MacEwan University, \\ Alberta, Canada \\ Sarah Fereja \\ BCYC, MacEwan University, \\ Alberta, Canada \\ Irene Mai \\ BCYC, MacEwan University, \\ Alberta, Canada \\ Alice Yuan \\ MacEwan University, \\ Alberta, Canada \\ Gerard Bellefeuille \\ Professor, \\ Department of Child and Youth Care MacEwan University, \\ Alberta, Canada
}

\begin{abstract}
In this article, we report on the innovative research design and results of a coursebased qualitative inquiry into child and youth care (CYC) students' experiences of maintaining a relational-centered practice stance while in a power-over position of authority. Qualitative data from two semi-structured focus groups as well as an artsbased data collection technique were analyzed using the thematic analysis method. The following four major themes were identified from the analyses: (a) "self-awareness is key," (b) "the mediating power of a positive trusting relationship," (c) "the vital importance of emotional safety," and (d) "it's a two-way street." The results of this course-based study revealed that, although CYC students are committed to practicing relationally, the dynamics of being in a position of power-over authority are complex and challenging to navigate.
\end{abstract}

Key words: authority, child and youth care, course-based, relational practice

\section{INTRODUCTION}

One of the most important elements of relational-centred child and youth care (CYC) practice is to be caring (Krueger, 1994; Stuart, 2013; Taggart, 2014). As fourth-year CYC students, we know that our involvement with children, youth, and families is based on our ability to be empathetic, trusting, and respectful-all essential features of a caring relationship. The title of "child and youth care practitioner" itself signifies that the act of caring is an intrinsic part of CYC practice; that is why CYC work in theory and practice is grounded both in a relational ontology of being-in-relation and a world view of unity and connectedness of all (Bellefeuille et al., 2017). The primary contention of relational ontology is the notion that the "self" is a 
process of relatedness or, as Bellefeuille and Jamieson explain, it is not so much a personal possession but rather a reflection of one's lifelong relational experiences. As CYC students who practice from a relational-centered perspective, we are constantly encouraged to challenge many of the assumptions that we have built up over time about what professional caring looks like. Most importantly, relational-centered practice dismisses the notion that "caring" can be separated from emotion. It further characterizes authenticity as having no separation of the self from the professional self (Bellefeuille, Ricks, \& Jamieson, 2012). Vincent (2016) exemplifies this by contending that the fundamental ethos of CYC caring is the expression of love, which he considers being the highest concept in human care because love originates from one's heart. He goes on to state that:

...expressing love has more to do with how a task is done, how the practitioner imbues love in the task than what the task is...expressing love involves more than the verbal communication of a practitioner's feelings. It involves translating feelings into actions (p. 16).

Vincent also points out that "love cannot grow in interactions where one party is intent on maintaining power over the other" (p. 17). Nevertheless, as CYC professionals, we are often in positions of authority or have authoritative responsibilities in our roles as residential staff, family support workers, and school aides, to mention a few, in which power is often used to manage behavior. Although we may not consider ourselves to be authority figures, we are in positions of authority, and, as such, maintaining a relational bearing is not always easy. The purpose of this course-based research project is therefore to ascertain what relational caring looks like when operating from a position of authority.

\section{UNDERGRADUATE COURSE-BASED RESEARCH: A PEDAGOGICAL TOOL USED TO FOSTER CRITICALITY, REFLECTIVITY, AND PRAXIS}

The Bachelor of Child and Youth Care program at MacEwan University is continuously searching for new pedagogical approaches to foster criticality, reflectivity, and praxis, all of which the program considers integral components of the overall student educational experience. As such, the design and implementation of a course-based approach, in contrast with the traditional didactic approach to research-methods instruction, offers fourth-year undergraduate students the opportunity to master introductory research skills by conceptualizing, designing, administering, and showcasing small, minimum-risk research projects under the guidance and supervision of the course instructor (commonly, a professor with an extensive background in research and teaching).

The use of course-based research in higher education has increased substantially in recent years (Allyn, 2013; Bellefeuille, Ekdahl, Kent, \& Kluczny, 2014; Harrison, Dunbar, Ratmansky, Boyd, \& Lopatto, 2010). The benefits derived from a course-based approach to teaching research methods for CYC students are significant. First, there is value in providing students with authentic learning experiences that enhance the transfer of knowledge learned in traditional education practice. For example, former students have reported that their engagement in course-based research enabled them to deepen their scientific knowledge by adopting new methods of creative inquiry. Second, course-based research offers students the opportunity to work with instructors in a mentoring relationship; one result is that a greater number of student's express interest in advancing to graduate studies. Third, results generated through course-based research can sometimes be published in peer-reviewed journals and online open-access portals and thereby contribute to the discipline's knowledge base.

The ethical approval required to permit students to conduct course-based research projects is granted to the course instructor by the university's research ethics board (REB). Student 
research groups are then required to complete an REB application form for each course-based research project undertaken in the class; each application is then reviewed by the course instructor and a sub-REB committee to ensure each course-based research project is completed and is in compliance with the ethics review requirements of the university.

\section{Research Design}

A research design describes the logic by which research is to be conducted. It involves the intersection of philosophy, strategies of inquiry, and specific methods in a coherent and logical way (Yin, 2003). This course-based inquiry used a qualitative cross-sectional design, embedded in the interpretative paradigm. Interpretive research is closely associated with qualitative studies and is concerned with understanding the world as it is from the subjective experiences of individuals (Creswell, 2003). Qualitative research is used to capture in-depth information about a phenomenon (Schwandt, 2000). It is a form of social inquiry that focuses on the way individuals interpret and make sense of their experiences and the world in which they live by employing meaning-making (versus measurement) oriented methodologies through interviewing as well as observational and increasingly expressive arts-based techniques (Coemans \& Hannes, 2017: Finley, 2001). According to Myers (2009), such inquiries allow understanding both the complexities of the different contexts within which the participants act and the way their contexts influence their actions.

\section{Statement of Research Question}

As CYC students, we are taught the theory and practice of relational practice; however, the relationship between the realities in which practice takes place and classroom learning is often difficult to capture. For this reason, this course-based inquiry focused on the following question: does our authority as CYC professionals influence our ability to demonstrate emotional care in relational-centred practice?

\section{Participants}

A non-probability purposive sampling strategy was used to recruit undergraduate CYC students at MacEwan University for this course-based research inquiry. Purposive sampling is one of the most common sampling strategies that is used in qualitative research for identifying and selecting "information-rich" participants from which the most can be learned (Patton, 2002). The target sample size of CYC students was 11 across all four years of the program of study.

\section{DATA COLLECTION STRATEGY}

The main data collection techniques used in this course-based inquiry were semi-structured focus groups and an arts-based activity.

\section{Semi-structure focus group}

In seeking to explore our research question in more depth than might occur in individual interviews, we decided to use a semi-structured focus group as our primary data collection strategy. Focus groups allow participants to build upon each other responses (Lederman 1990). As Lederman (1990) explains, "the data generated in focus group interviews are often richer and deeper than data elicited in the one-on-one interview situation" (p.119). Focus groups, according to Osborne and Collins (2001), are also considered to be less threatening than individual interviews because the presence of peers lends support and security, encouraging less talkative individuals to speak up. Semi-structured focus groups involve openended guiding questions at the start to avoid undue influence on participants' thinking, followed by the careful use of follow-up questions to elicit more information (Kidd \& Parshall, 2000). In the present study, participants were randomly divided into two focus-groups of six. 
Both focus groups comprised participants from all four years of the CYC program of study. The focus groups were audio-recorded using a password-protected smartphone.

\section{Arts-based activity}

An expressive arts-based method was used to allow participants another means to articulate or express themselves in response to the research question. As argued by Jones and Leavy (2004), arts-based research is "any social research or human inquiry that adapts the tenets of the creative arts as a part of the methodology ... the arts may be used during data collection, analysis, interpretation and/or dissemination" (pp.1-2). According to Leavy (2009), arts-based data collection methods can include, to name but a few, the use of poetry, drawing, sculpting, music, visual art, drama, and dance. Cohenmiller (2018) and Dunn and Mellor (2017) argue that arts-based research methods can add value when it comes to answering research questions that draw upon the emotional and symbolic aspects of participants' experiences or cannot (or, at least, not fully) be answered using more traditional research methods. Similarly, Finley and Knowes (1995) view the arts as a valuable means for communicating complex social phenomena because of their ability to assist in the expression of the lived experience.

In this stage of the data collection process, participants were invited to create a piece of art that captured their emotional reaction to the research question (see figure 1).

Participants were provided with a selection of figurines and playthings as well as different colours of clay.

\section{Figure 1. Arts-based data collection method}
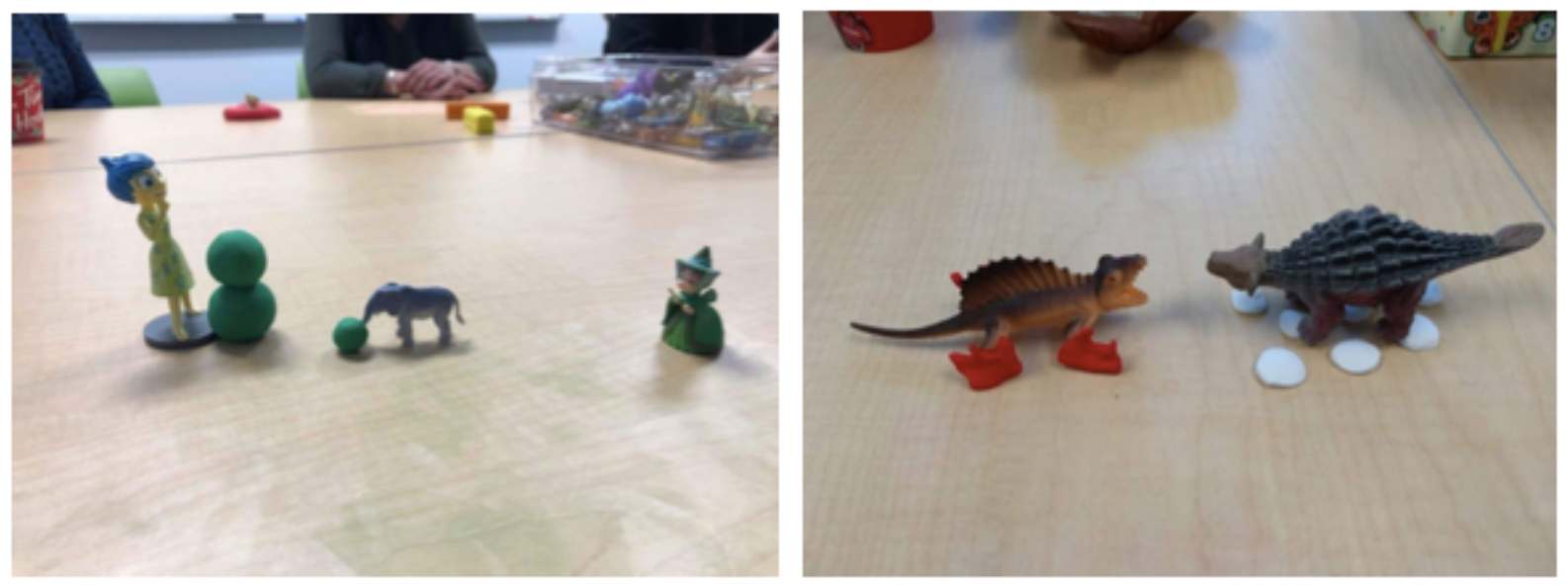

\section{DATA ANALYSIS}

A principal characteristic of data analysis in qualitative research located within the interpretive paradigm is the search for meaning through the direct interpretation of what is observed and what is experienced and reported by the research participants. Creswell (2009), for instance, writes that "qualitative research is a means for exploring and understanding the meaning individuals or groups ascribe to a social or human problem" (p.4). Hence, in qualitative research, thematic analysis methods are likely to be the best-suited approaches to data analysis. The six-step thematic analysis process defined by Braun and Clark (2006) was used to identify the following four themes: (a) "self-awareness is key," (b) "the mediating power of a positive relationship," (c) "the vital importance of emotional safety," and (d) "balance of power." 


\section{Self-awareness is key}

The most dominant theme was the importance of having a high degree of self-awareness. Selfawareness was seen as a cornerstone for having the capacity to recognize and accept that CYC practitioners do in fact hold positions of authority and have to a certain degree power-over children, youth, and families. It was noted that

one's personal perspective regarding the nature of authority will greatly impact how they will manage their authority in the context of creating caring relationships. For example,

one participant explained that authority is often defined only in negative terms, and as a form of domination, but it can also be a positive force for individual and collective capacity to act for change. This participant stated, "if having authority is viewed as being an agent for change, then it can pave the way for practitioners to demonstrate positive and meaningful acts of care." On the other hand, participants also noted that having negative associations about the use of authority, such as repression, force, coercion, discrimination, corruption, and abuse, can result in CYC practitioners wanting to be seen as a friend rather than a worker, which will most likely result in a lack of caring within the context of building caring relationships. As one participant stated, "in order to build a caring relationship and to truly offer care, the relationship itself needs to be viewed as a partnership." The consensus was that while being in a position of authority can be translated as having "power-over" children, youth, and families, CYC practitioners can be in a position of authority yet use that authority to set appropriate boundaries and make all decisions necessary to maintain the well-being of children, youth, and families who actually require the support services of a CYC professional.

\section{The mediating power of a positive trusting relationship}

A second dominant theme was how vital it is to develop a positive rapport and to establish trust as prerequisites to forming a caring relationship. Participants noted that there are various challenges in residential care, for instance, that make it difficult to form positive rapport and trust. This difficulty is due to the behavior related to the management responsibilities that are inherent in this type of CYC work; however, without trust and some level of positive rapport, developing a caring relationship is not possible. As many of the participants pointed out, having positive and trusting relationships with others is precisely what children, youth, and families have been most often deprived to the extent of losing their own ability and confidence to establish and maintain positive relationships. It was, therefore, suggested that they need to experience unconditional acceptance and kindness if they are to be able to learn to trust again and relate positively to others. One participant used the "filling the bucket" metaphor to explain the importance of building positive relationships. Participants explained how a child's, youth's, or family's emotional bucket is to be filled with as many acts of kindness, helpfulness, and respect. As one participant expressed, "as practitioners, we have a responsibility to fill up the bucket until it's overfilled."

\section{The vital importance of emotional safety}

A third theme was the importance of creating a safe environment as an important aspect of being in a position of authority. Participants from one of the focus groups stated that "CYC practitioners create a sense of security and safety when they are able to balance being both relational and authoritative." Participants conveyed that when they act on their authority, they are attempting to create an environment of safety. For example, participants noted that exercising authority by setting boundaries and expectations can be a way for practitioners to help children, youth, and families feel safe and avoid self-harming behaviors. However, participants also noted that in creating a safe place for children, youth, and families to grow they must have the skills and self-awareness to use their authority in a relational manner. 


\section{A two-way street}

The fourth and final theme was "it's a two-way street." An example is given by one participant who said, "you do not build a caring relationship on your own; it's a two-way street." Building trust comes in the form of "practicing what you preach," listening more than talking, keeping promises, and showing appreciation for honesty. CYC workers can breach trust with their clients, too; these breaches often come in the forms of outbursts, guilt trips, threats, inconsistency, and violations of privacy. CYC workers and teens alike will make mistakes and be perfectly imperfect.

\section{METHODOLOGICAL TRUSTWORTHINESS}

The traditional criteria for ensuring the methodological rigor-objectivity, reliability, and validity are not applied to qualitative studies that are interested in questioning and understanding the meaning and interpretation of phenomena (Patton, 2002). As Lincoln and Guba (1985) explain, the criteria of one research paradigm cannot be usefully applied to another research paradigm. Van Manen (2003) further notes that rigorous conduct should not only encourage the researcher to justify the relationship between the methodology and study design but also encourage the endpoint of the research-the text-to "stand up for the uniqueness and significance of the notion to which it has dedicated itself" (p. 18). Hence, for the purpose of this course-based inquiry, we drew upon Lincoln and Cuba's (1985) four criteria of methodological trustworthiness: credibility, transferability, dependability, and confirmability.

\section{Credibility}

The notion of credibility in qualitative research (the counterpart of internal validity) is defined as the extent to which the data and data analysis are believable and trustworthy. It refers to both the credibility of findings as "known, experienced, or deeply felt by the people being studied" (Leininger, 1994, p. 105) and the efforts to demonstrate the "fit" between participants' views and the researcher's representation of them. The use of triangulation enhanced credibility through different data collection strategies.

\section{Transferability}

Transferability (comparable with external validity) refers to the degree to which particular findings from an interpretive study" can be transferred to another similar context or situation and still preserve the particularized meanings, interpretations, and inferences" (Leininger, 1994 , p. 106). Transferability was established by providing rich and thick verbatim descriptions of participants' responses.

\section{Dependability}

Dependability (analogous to reliability) refers to the consistency of observing the same finding under similar circumstances (Merriam, 1998). Evidence of dependability includes a documented audit trail consisting of detailed voice recordings and note-taking of data collection and data analysis processes.

\section{Confirmability}

Confirmability is "the degree to which its findings are the product of the focus of its inquiry and not of the biases of the researcher" (Erlandson et al., 1993, p. 34). A range of strategies was used to enhance the confirmability of the study. First, the interpretive research paradigm was an appropriate theoretical framework to seek insights into the phenomenon of inquiry. Second, the data collection and analysis research methods were congruent with the philosophical foundations of the qualitative interpretive paradigm. Third, the research findings were reported within the context of the stated researcher biases or pre-understandings (e.g., 
assumptions, world views, biases, theoretical orientations, values, and epistemological stances).

\section{DISCUSSION}

The overall consensus amongst the participants was that it is possible to be in a position of authority and maintain caring relationships. The majority of participants felt that, when authority needed to be exercised, as long as it was purposeful and meaningful, that it could be viewed as caring. Using authority as a means of maintaining safety was also viewed as a demonstration of care. The forming of positive relationships was seen as the most important factor in being able to use authority without it being felt as uncaring. Overall, the results of this course-based research study gave insight into some of the different factors that can contribute to the use of authority and how that authority is perceived. Authority is more than the simple explanation of exercising power.

\section{References}

Bellefeuille, G. and D. Jamieson, 2008. Relational centred-planning: A turn toward creative potential and possibilities. In G. Bellefeuille \& F. Ricks (Eds.), Standing on the precipice: Inquiry into the creative potential of child and youth care practice (pp. 35-72). Edmonton, AB: MacEwan Press.

Bellefeuille, G., Ricks, F., \& Jamieson, D. (Eds.). (2012). Standing on the precipice: Inquiry into the creative potential of child and youth care practice (2nd ed.). Edmonton. AB: MacEwan Press.

Bellefeuille, G., Stiller, B., Neuman, S., Deol, J., Smith, C., Brown, M., Gautreau, \& Diduch, A. (2017). Building a child and youth care culture of relational-centred praxis: Ours to make. American Journal of Education and Learning, 2(1), 43-64.

Bernard, H. R. (2002). Research methods in anthropology: Qualitative and quantitative approaches (3rd ed.). Walnut Creek, CA: Alta Mira Press.

Braun, V., \&Clarke, V. (2006). Using thematic analysis in psychology. Qualitative Research in Psychology, 3(2), 77101.

Coemans, S. \& Hannes, K. (2017). Researchers under the spell of the arts: Two decades of using arts-based methods in community-based inquiry with vulnerable populations. Educational Research Review, 22, 34-49.

CohenMiller, Anna S. (2018). Visual arts as a tool for phenomenology. Forum Qualitative Sozialforschung / Forum: Qualitative Social Research, 19(1), Art. 15.

Dunn, Valerie \& Mellor, Tom (2017). Creative, participatory projects with young people: Reflections over five years. Research for All, 1(2), 284-299.

Finley, S. (2011). Critical arts-based inquiry. In N. K. Denzin \& Y. S. Lincoln, The Sage handbook of qualitative research (pp.435-450). Los Angeles, CA: Sage.

Garfat, T. (2003). Four parts magic: The anatomy of a child and youth care Intervention. CYC Online: Journal of the International Child \& Youth Care Network, 50,1-31.

Krueger, M. (1994). Rhythm and presence: Connecting with children on the edge. Journal of Emotional and Behavioral Problems, 3(1), 49-51.

Miles, M. B., \& Huberman, A. M. (1994). Qualitative data analysis: An expanded sourcebook (2nd ed.). Thousand Oaks, CA: Sage

Patton MQ. (2002). Qualitative research and evaluation methods (3rd. ed.). Thousand Oaks, CA: Sage.

Smith, M. (2006). Act justly, love tenderly, walk humbly. Relational Child and Youth Care Practice 19(4), 5-16.

Stuart, C. (2013). Foundations of child and youth care (2nd edition). Dubuque, IA: Kendall Hunt Publishing Company.

Schwandt, T. A. (2000). Three epistemological stances for qualitative inquiry: Interpretivism, hermeneutics, and social constructionism. In N.K. Denzin and Y.S. Lincoln (Eds.), Handbook of qualitative research (pp. 189-214).

Thousand Oaks, CA: Sage.

Taggart, G. (2014). Compassionate pedagogy: The ethics of care in early childhood professionalism. European Early Childhood Education Research Journal. 12(2), 81-95. 
Vincent, J. (2016). Perspectives on love as a component of professional practice Scottish Journal of Residential Child Care, 15(3), 6-21.

Yin, R. K. (2003). Case study research: Design and methods (3rd ed.). Thousand Oaks, CA: Sage 